\title{
Results and perspectives of tectonomagnetic investigations in the Western Antarctic
}

\author{
Valentin Yu. Maksymchuk ( $\left.{ }^{1}\right)$, Vladimir G. Bakhmutov $\left({ }^{2}\right)$, \\ Yurij M. Horodyskyy $\left({ }^{1}\right)$ and Ihor O. Chobotok $\left({ }^{1}\right)$ \\ (') Carpathian branch of S.I.Subbotin's Institute of Geophysics, Ukrainian National Academy of Sci., Lviv, Ukraine \\ $\left.{ }^{2}{ }^{2}\right)$ S.I.Subbotin's Institute of Geophysics, Ukrainian National Academy of Sci., Kyiv, Ukraine
}

\begin{abstract}
The results of long-term (1998-2005 yrs.) tectonomagnetic investigations in the Western Antarctic near the location of Ukrainian Antarctic Station «Academic Vernadsky» are reviewed. The peculiarities of the Earth's anomalous magnetic field and its dynamic temporal variations (tectonomagnetic anomalies) were studied using the newly founded tectonomagnetic polygon. Near the Argentine Archipelago intensive tectonomagnetic effects up to $-2.8 \mathrm{nT} /$ year were determined. Their spatial-temporal structure agrees with tectonic structure elements. We suggest that the nature of such effects is caused by a piezomagnetic effect under the influence of stretching tectonic forces (few bars per year) in sub-latitudinal direction. Perspectives of tectonomagnetic investigations in the region are discussed.
\end{abstract}

Key words tectonomagnetic anomaly - geodynamics - stretching tectonic forces

\section{Introduction}

Tectonomagnetic investigations at the location of the Ukrainian Antarctic station «Academic Vernadsky» (UAS) form part of the studies of recent geodynamic processes in the Earth's crust of the region. The area of the tectonomagnetic investigations is located near the West coast of the Antarctic Peninsula that is a part of the Western Antarctic folded system, extended along Pacific Ocean shore. The Antarctic continent belongs to low seismic activity regions. Nevertheless, a new (Mezo-Cenozoic) volcan-

Mailing address: Dr. Valentin Yu. Maksymchuk, Carpathian branch of S.I.Subbotin's Institute of Geophysics, Ukrainian National Academy of Sci., Lviv, Ukraine; email: depart10@cb-igph.lviv.ua ism, existent in this region (active volcano Erebus, neo-volcanism activity in the Brancefield strait, etc.) indicates the presence of active tectonic processes in the regions crust. Geomorphologic, bathymetric and geophysical data near the location of UAS has defined the region important for recent geomorphological structural elements - rift grabens, deep faults and lineaments.

A tectonomagnetic method has its own place among geophysical methods. It is widely used for investigations, and mapping of active tectonic fault zones, of seismic-tectonic processes and solving other problems concerning geology and geodynamics (Parkinson (1983), Skovorodkin (1985).

The specific geographical and climate conditions in the Antarctic region, complicate geophysical investigations. That is why the deep structure and recent geodynamics of the crust in the region were insufficiently studied, and geodynamic investigations near UAS were not fulfilled at all. In the frame of the Ukrainian $\mathrm{Na}-$ 
tional Program of investigations in the Antarctic at the location of UAS and surrounding areas, work began in 1998 for setting the foundation of geophysical and geodynamic polygons, including organization of tectonomagnetic monitoring and tectonomagnetic profiling. Investigations were fulfilled during seasonal Antarctic expeditions. During 1998-2005 a network of 14 tectonomagnetic stations was created and 6 cycles of geomagnetic observations have subsequently been made.

\section{Fundamentals of tectonomagnetic investigations and methods}

The term tectonomagnetism was proposed by Nagata (1969) to denote the local geomagnetic field variations, caused by tectonic processes in the Earth's crust. Since then methods of tectonomagnetic investigations have been widely developed.

Results of magnetic field temporal changes have been investigated in various regions of the World and have shown that all tectonomagnetic anomalies can be classified as: 1) magnetic field variations caused by slow tectonic processes and recent movements of the crust; 2) anomalous variations of the magnetic field related to seismotectonic processes-seismomagnetic effects; 3) magnetic field variations related to volcanic eruptions-volcanomagnetic effects; 4) magnetic field variations, caused by electrodynamic processes in the regions of electroconducting anomalies, etc.

The duration of tectonomagnetic anomalies vary in the range from minutes to decades, their amplitudes-from a few to several tens of nanoteslas. Extensions of tectonomagnetic anomalies reach tens and even hundreds of kilometers. The tectonomagnetic anomalies are mainly caused by the variations of the stress-strain state of rocks resulting in piezomagnetic or electrokinetic effects.

Piezomagnetic effects result in changing the magnetization vector of rocks. This effect has been well studied and is often applied to estimate stress changes by tectonomagnetic data (Hao Jinqi et al. (1982); Sasai (1983); Parkinson (1983); Skovorodkin (1985); Maksymchuk et al. (2001)).
Electrokinetic effects result from motion of fluids in porous rocks. Such phenomena in electroneutral systems exist because of the existence of a double electric layer (DEL) near the solid and liquid phase boundary. This effect may cause observable magnetic anomalies (Martin et al. (1982); Mizutani and Ishido (1976); Murakami (1989)), especially in sedimentary basins.

The absence of sedimentary complexes and outcrops of abyssal rocks is peculiar to the Argentine Islands archipelago and the west slope of the Antarctic Peninsula, where the research area is located. Thus, we believe that the influence of the electrokinetic effect is negligible.

Classical methods of tectonomagnetic investigations consist of synchronous measuring of the magnitude of total geomagnetic field vectors on a fixed network of points $\left(\mathrm{F}_{\mathrm{p}}\right)$ and a reference (basic) point $\left(\mathrm{F}_{\mathrm{b}}\right)$ through definite time intervals. Such a scheme generally allows elimination of the influence of external magnetic field variations in differences $\Delta \mathrm{F}=\mathrm{F}_{\mathrm{p}}-\mathrm{F}_{\mathrm{b}}$. Objective values of tectonomagnetic measurements are variations of $\Delta \mathrm{F}$ between pairs consecutive observation cycles $\left(\Delta \Delta \mathrm{F}=\Delta \mathrm{F}_{2}-\Delta \mathrm{F}_{1}\right)$. Repeated measurements were done once per year, during summer season expeditions. Therefore, these measurements were aimed at defining long-period (more then 1 year) temporal variations of the anomalous magnetic field.

Tectonomagnetic points were founded mainly on the Argentine Islands archipelago. These points form two tectonomagnetic profiles: sub-latitude profile I (Barchany-Rasmussen), $11 \mathrm{~km}$ long with 7 points and 6 observations cycles (1998-2005), and sub-meridian profile II (Barthelot isl.-Petermann isl.) with 7 points and 3 observations cycles (2002, 2004, 2005) (fig.1). The basic point was the magnetic observatory «Argentine Islands» (AIA), located on the intersection of profiles I and II. The registration of the total field $\mathrm{F}$ at the basic point was fulfilled with proton magnetovariational station MV-01 (sensitivity 0.1 $\mathrm{nT}$ ). Measurements on all other points were done by a proton magnetometer MMP-203 (sensitivity $1 \mathrm{nT}$ ). The mean-square error was $0.7 \mathrm{nT}$. 


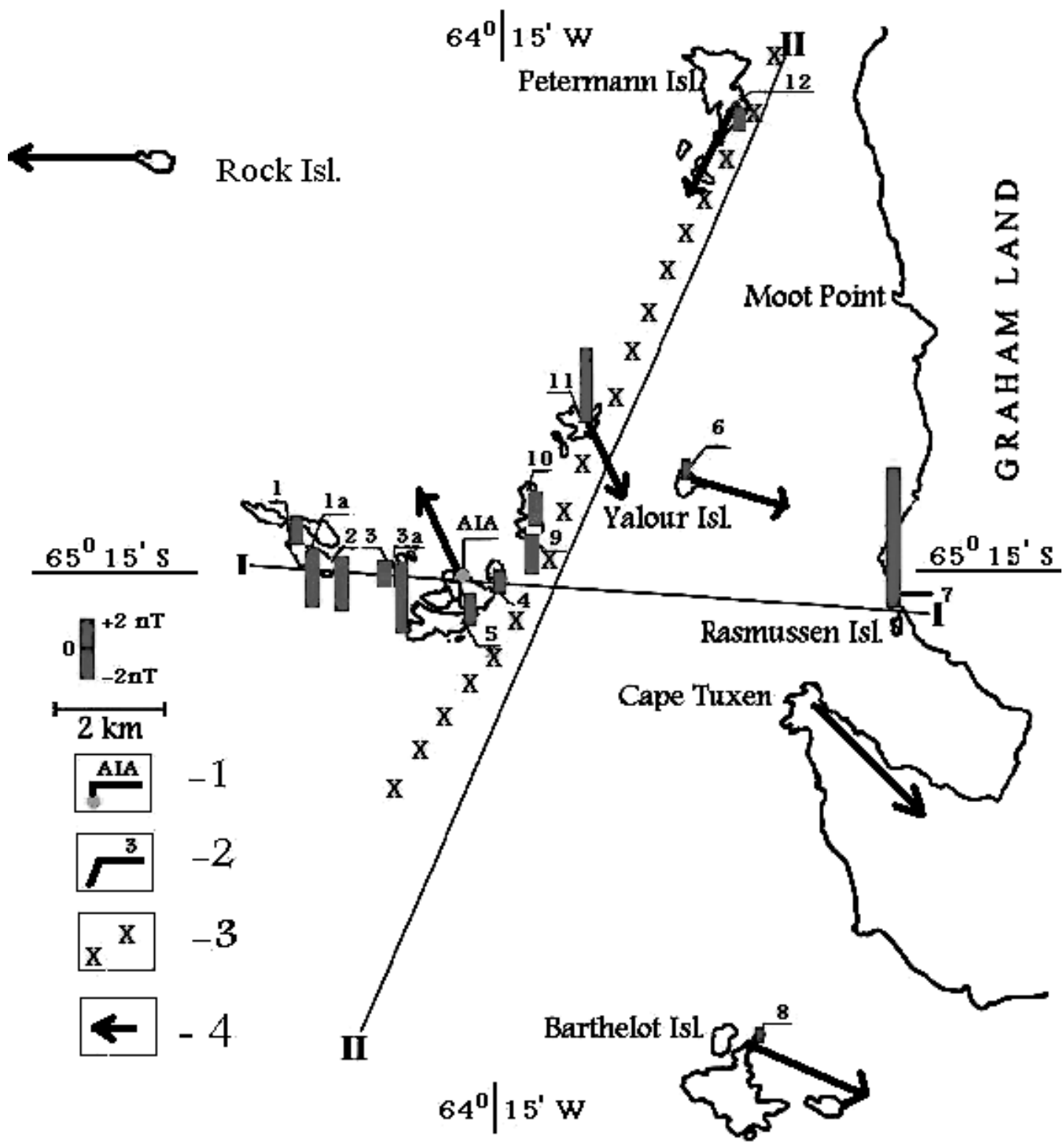

Fig. 1. Antarctic tectonomagnetic polygon and temporal variations of geomagnetic field $(\Delta \Delta \mathrm{F})$ in $2004-2005$. 1 magnetic observatory AIA, 2 tectonomagnetic points, 3 prognoses fault line, 4 vectors of geodetic points displacements (Tretyak et al., 2006).

3. Results and interpretation of tectonomagnetic observations

Geomagnetic observations, carried out during 1998-2005, gave an opportunity for investi- gations of temporal-spatial peculiarities of tectonomagnetic variations. Tectonomagnetic network was created step by step from 7 points in 1998 to 14 points in 2005, so the number of observations for each point varies (fig. 2). Geo- 
Table I. The results of measurements of differential geomagnetic field DF in the tectonomagnetic polygon in the location of UAS

\begin{tabular}{|c|c|c|c|c|c|c|c|c|}
\hline $\begin{array}{l}\text { Point } \\
\text { No. }\end{array}$ & $\begin{array}{l}\text { Location } \\
\text { (1998) }\end{array}$ & $\begin{array}{l}\text { Coordinates } \\
(2001)\end{array}$ & $\begin{array}{l}\Delta \mathrm{F} 1, \mathrm{nT} \\
(2002)\end{array}$ & $\begin{array}{l}\Delta \mathrm{F} 2, \mathrm{nT} \\
(2003)\end{array}$ & $\begin{array}{l}\Delta \mathrm{F} 3, \mathrm{nT} \\
(2004)\end{array}$ & $\begin{array}{l}\Delta \mathrm{F} 4, \mathrm{nT} \\
(2005)\end{array}$ & $\Delta \mathrm{F} 5, \mathrm{nT}$ & $\Delta \mathrm{F} 6, \mathrm{nT}$ \\
\hline 1 & $\begin{array}{l}\text { Barchany isl. (southern), } \\
\text { West }\end{array}$ & $\begin{array}{l}\text { S } 65^{\circ} 14.362^{\prime} \\
\text { W } 64^{\circ} 19.023\end{array}$ & 294.7 & 293.8 & 289.2 & 292.1 & 287.3 & 289.4 \\
\hline $1 \mathrm{a}$ & $\begin{array}{l}\text { Barchany isl. (southern), } \\
\text { Center }\end{array}$ & $\begin{array}{l}\text { S } 65^{\circ} 14.410^{\prime} \\
\text { W } 64^{\circ} 18.447^{\prime}\end{array}$ & & & 328.6 & 326.7 & 325.7 & 321.6 \\
\hline 2 & $\begin{array}{l}\text { Barchany isl. (southern), } \\
\text { East }\end{array}$ & $\begin{array}{l}\text { S } 65^{\circ} 14.544^{\prime} \\
\text { W } 64^{\circ} 17.862\end{array}$ & 128.5 & 127.2 & 125.0 & 127.6 & 126.6 & 123.0 \\
\hline 3 & $\begin{array}{l}\text { «Tree Little Pigs» isl." } \\
\text { (western) }\end{array}$ & $\begin{array}{l}\text { S } 65^{\circ} 14.617^{\prime} \\
\text { W } 64^{\circ} 16.855^{\prime}\end{array}$ & 581.4 & 574.1 & 567.7 & 570.9 & 564.6 & 562.9 \\
\hline $3 a$ & $\begin{array}{l}\text { «Tree Little Pigs» isl." } \\
\text { (western) }\end{array}$ & $\begin{array}{l}\text { S } 65^{\circ} 14.630^{\prime} \\
\text { W } 64^{\circ} 16.761^{\prime}\end{array}$ & & & 531.2 & 535.4 & 531.5 & 526.6 \\
\hline 4 & Pinguin-Point isl. & $\begin{array}{l}\text { S 65⒕919' } \\
\text { W } 64^{\circ} 14.332^{\prime}\end{array}$ & 75.3 & 76.5 & 77.6 & 77.2 & 75.7 & 77.5 \\
\hline 5 & Skua isl. & 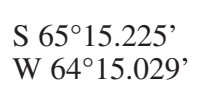 & 40.1 & 41.0 & 40.4 & 41.5 & 36.6 & 38.7 \\
\hline 6 & О-в Ялур & $\begin{array}{l}\mathrm{S} 65^{\circ} 14.035^{\prime} \\
\mathrm{W} 64^{\circ} 09.715\end{array}$ & 276.3 & 278.9 & 277.0 & 279.4 & 278.2 & 279.7 \\
\hline 7 & Rasmussen cape & $\begin{array}{l}\text { S } 65^{\circ} 14.852^{\prime} \\
\text { W } 64^{\circ} 05.097^{\prime}\end{array}$ & 1014.9 & 1015.5 & & 1015.9 & 1019.2 & 1028.8 \\
\hline 8 & Barthelot isl. & $\begin{array}{l}\text { S 65⒚436' } \\
\text { W 640.419 }\end{array}$ & & 746.7 & & 752.7 & 747.2 & 748.0 \\
\hline 9 & Uruguay isl. (south) & 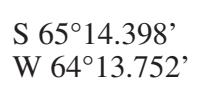 & & 50.4 & 51.3 & & 54.4 & 51.5 \\
\hline 10 & Uruguay isl. (north) & $\begin{array}{l}\text { S } 65^{\circ} 14.005^{\prime} \\
\text { W } 64^{\circ} 13.389^{\prime}\end{array}$ & & & 211.1 & & 210.8 & 208.0 \\
\hline 11 & Iryzar isl. & $\begin{array}{l}\mathrm{S} 65^{\circ} 13.186^{\prime} \\
\mathrm{W} 64^{\circ} 11.710\end{array}$ & & & 272.0 & & 274.0 & 279.5 \\
\hline 12 & Petermann isl. & $\begin{array}{l}\text { S } 65^{\circ} 10.501 \\
\text { W } 64^{\circ} 08.258^{\prime}\end{array}$ & & & & 332.14 & 339.1 & 337.6 \\
\hline
\end{tabular}

magnetic observations data are given in table I.

Dynamics of the magnetic field $F$ was investigated more completely along the sub-latitude profile I Barchany-Rasmussen. It crosses the main rock complexes and tectonic structures of the coastal shelf zone. The intensity and morphology of the local magnetic field temporal changes during 1998-2005 greatly varies in the different parts of the profile I (fig. 3). The most intensive variations of $\Delta \mathrm{F}$ were detected in points 1, 1a, 3, 3a (fig. 2), located in the western part of a working area. At point 3 during $1998-2005 \Delta \mathrm{F}$ decreased by $18.5 \mathrm{nT}$. It is noteworthy that the time changes of $\Delta \mathrm{F}$ for the 


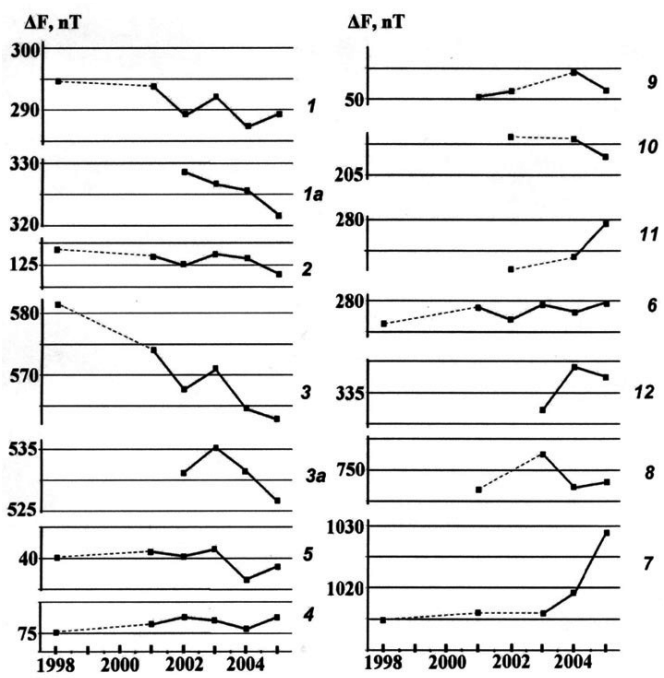

Fig. 2. Dynamics of geomagnetic field $\Delta \mathrm{F}$ in the points of the Antarctic tectonomagnetic polygon. points $3 \mathrm{a}$ and 3 , located near one another, were almost identical. This fact testifies the reliability of the results obtained.

Time changes of $\Delta \mathrm{F}$ in the eastern part of the region (points $4,9,6,7$ ) are rather monotonous. Thus, for point $6, \Delta \mathrm{F}$ increased by 3.6 nT (fig. 2) during 1998-2005. However the increasing of $\Delta \mathrm{F}$ of point 7 by $9.6 \mathrm{nT}$ during 2004-2005 is questionable on account of rather small changes in $\Delta \mathrm{F}$ here (less than $1.0 \mathrm{nT}$ ) before 2004.

Except for the trend one can see local peculiarities of $\Delta \mathrm{F}$ time changes in some points. Such peculiarities took place in 2002 in points $1,2,3,3 \mathrm{a}$. The maximum deviation of $\Delta \mathrm{F}$ from the trend that was defined for point 3 exceeded $5 \mathrm{nT}$. In $2003 \Delta \mathrm{F}$ in these points returns to the trend level. It is likely that in the vicinity of Three Little Pigs Island a local effect occurred in $\Delta \Delta \mathrm{F}$ field.

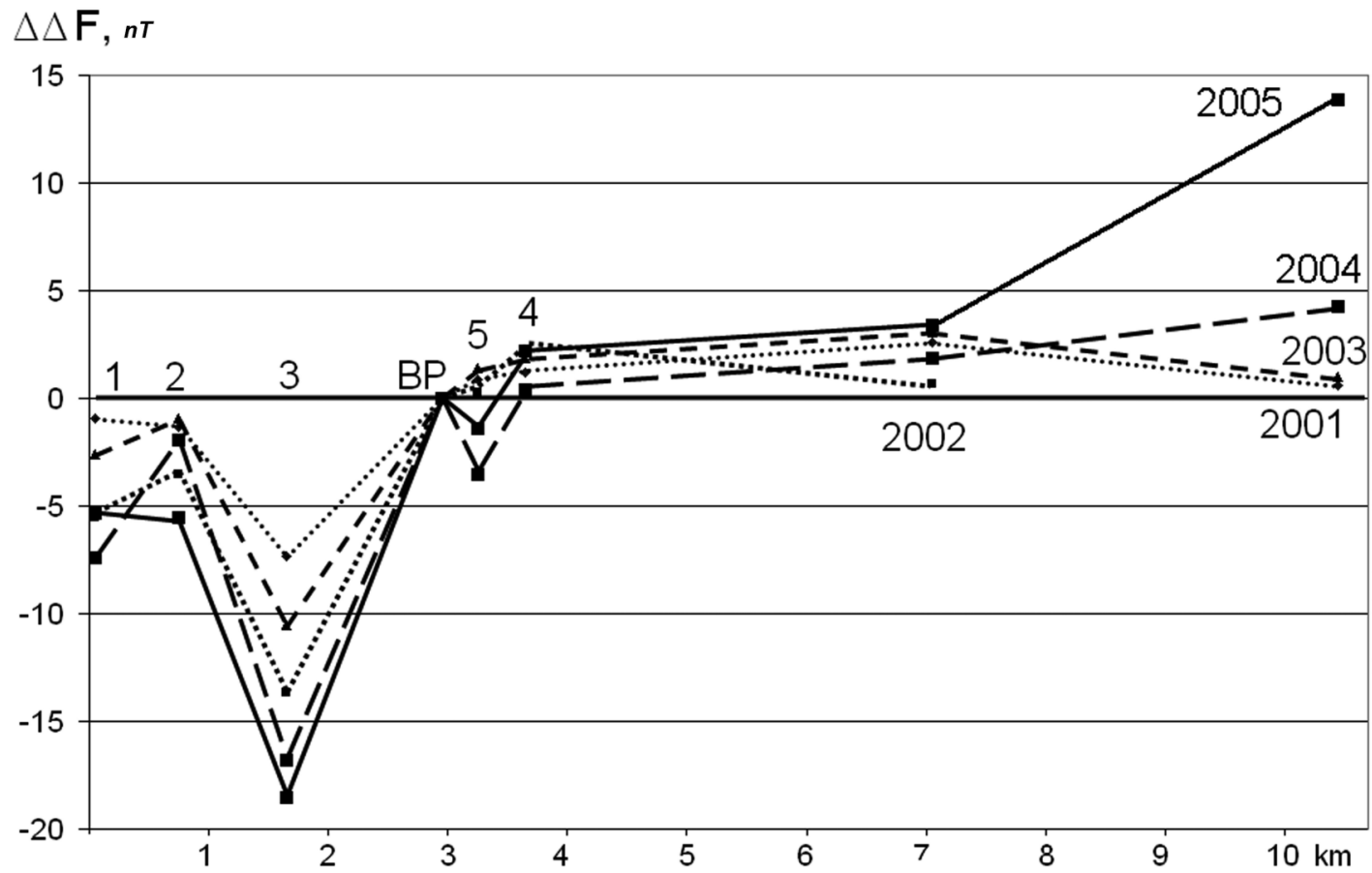

Fig. 3. Distribution of geomagnetic field temporal variations $(\Delta \Delta \mathrm{F})$ along the profile I - I (Barchany-Rasmussen) during 2001-1998; 2002-1998; 2003-1998; 2004-1998; 2005-1998. 
The spatial distribution of $\Delta \Delta \mathrm{F}$ field along profile I has some regularities intrinsic for all time intervals and for the summary curve of $\Delta \Delta \mathrm{F}$ (1998-2005) as well (fig. 3). The Eastern part of the profile (points 5, 4, 6, 7) is generally characterized by low positive values of $\Delta \Delta \mathrm{F}$ about 2-3 nT. $\Delta \Delta \mathrm{F}$ field in the western part of the profile (points $1,2,3$ ) has a very uneven shape with changes from -5.1 nT (point 2) to $18.5 \mathrm{nT}$ (point 3). One can notice the likeness of $\Delta \Delta \mathrm{F}$ curves for period of $1998-2001$ and of summary $\Delta \Delta \mathrm{F}$ curve $(1998-2005)$. The only difference is that amplitude of summary $\Delta \Delta \mathrm{F}$ anomaly is almost twice as large. Thus, in point $3 \Delta \Delta \mathrm{F}$ field had changed from -7.3 nT (19982001) to $-18.5 \mathrm{nT}$ (1998-2005).

Detailed measurements around the tectonomagnetic points have shown, that in some areas $\Delta \mathrm{F}$ field is highly diverse, with gradients up to 20-40 nT/m, resulting from high- and low-magnetized volcanic rocks. The rocks of the eastern part of the archipelago consist of andesites trachytes, porphyritic andesites, and crystal dacite tuffs. The rocks in the western part of the archipelago are mostly of a mezo- earlier-Cenozoic intrusion complex, such as gabbro and granite-diorites. Values of magnetic susceptibility of the rocks vary from 0.01 to 0.04 SI, and its natural residual magnetization - from 0.1 to $1.0 \mathrm{~A} / \mathrm{m}$, but these values may differ by a factor of 100 for rocks from the same islands. The zone of contact between volcanic rocks and a mezo- earlier-Cenozoic intrusion complex is located in the area of Shelter Island - Three Little Pigs Island - Indicator Island - Grotto Island and further to the north of Uruguay Island. At this contact zone, which is nearly $1000 \mathrm{~m}$ wide, local $\Delta \mathrm{F}$ anomaly of about $600 \mathrm{nT}$ in the Three Little Pigs Island area was detected.

An analysis of the spatial-temporal $\Delta \Delta \mathrm{F}$ structure distinguishes some zones of similar tectonomagnetic effects. First of all these are western and eastern blocks with the imaginary boundary along a line Galindez Island - Petermann Island. At the eastern block values of $\Delta \Delta \mathrm{F}$ usually are positive, and at western block - negative. Probably, these blocks are separated from other adjusting blocks by tectonic disjunctions. The scheme of tectonic fault location, based on the tectonomagnetic data, is shown in the fig. 1. In general, this is not in contradiction with geological data, accordingly with which along Penol Strait in north-east direction lies tectonic disjunction, clearly mapped on the maps of the sea-floor. But there are no reliable data about the location of this disjunction, its depth, declining angles, etc. Thus, based on the results of tectonomagnetic investigations, we may suppose, that this fault lies somewhat to the west. It is possible that the chain of volcanic islands along the line Skua Island - Petermann Island is connected with the western edge of this fault (fig. 1).

We are inclined to suppose that the described tectonomagnetic anomalies are of piezomagnetic nature. This supposition is grounded on the absence of sedimentary complex, as a condition of electrokinetic phenomena, and agrees with the distributions of $\Delta \Delta \mathrm{F}$ and local magnetic field $\Delta \mathrm{F}$ along the profile (fig. 4). For evaluation of possible contributions of the piezomagnetic effect into changing rock magnetization we accepted the $\Delta \mathrm{F}$ anomaly source as a set of vertically magnetized parallelepipeds of infinite spreading in a sub-meridian direction (fig. 4). The magnetization for parallelepiped No. 2 was accepted equal to $-0.78 \mathrm{~A} / \mathrm{m}$ and for all others $-0.55 \mathrm{~A} / \mathrm{m}$. The calculated $\Delta \Delta \mathrm{F}$ curve refers to following changes of the parallelepipeds magnetization (in $\mathrm{A} / \mathrm{m}$ ) 0.004, 0.0068, 0.003, 0.0015, 0.0003, 0.001 from No.1 to No.6. The evaluation of strain, using the method in Parkinson (1983) and Skovorodkin (1985) suggested that the magnetization change in parallelepiped No. 2 may be caused by variation of horizontal strains about $-25-30$ bar. So, we conclude that in the observation area during seven years (19982005) local variations of stretching strains with an average velocity near 5 bar per year took place.

To explain the nature of tectonomagnetic effects in a location of UAS it is necessary to clarify the recent tectonic evolution of this region, connected with processes in the Bransfield Strait. Accordingly, with traditional ideas about this part of the Western Antarctic as a tectonomagnetic arc, its formation was prolonged by subduction of the oceanic Proto-Pacific plate under the margin of the Antarctic plate. Results 

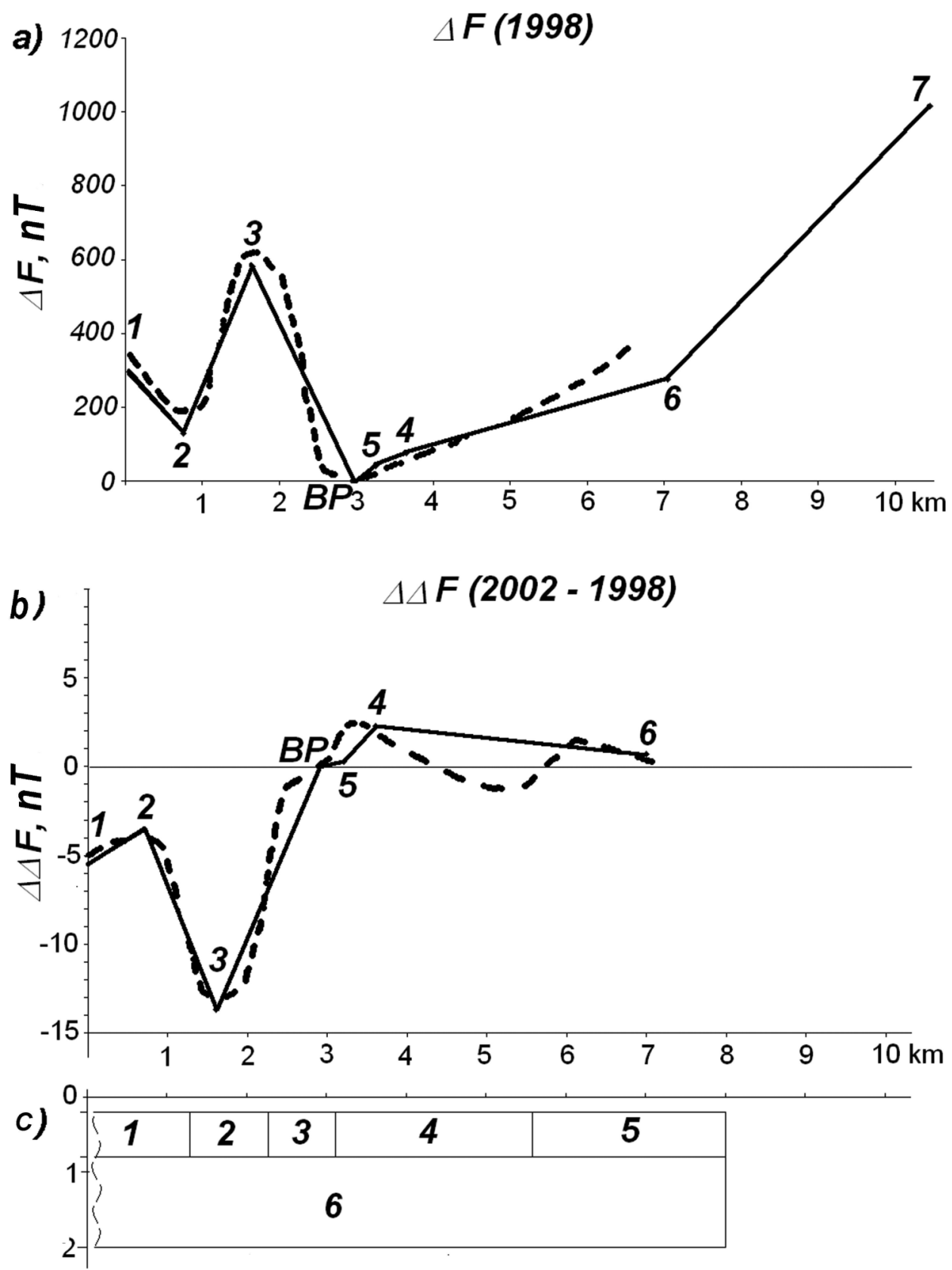

$\mathrm{H}, \mathrm{km}$

Fig. 4. The results of anomalous magnetic field $(\Delta \mathrm{F})$ and its temporal variations $(\Delta \Delta \mathrm{F})$ interpretation in the profile I - I (Barchany-Rasmussen)

a) observed and calculated (dashed) curves of $\Delta F, b$ ) observed and calculated (dashed) curves of $\Delta \Delta F$ along the profile $I-I, c)$ a model of anomalies source. 
of bathymetry, high-precision geodetic measurements, seismic data, materials of seismic tomography show, that Bransfield Strait was formed through active stretching of about 10 $\mathrm{mm}$ per year in NW-SE direction.

The central part of the strait contains a 20$25 \mathrm{~km}$ width zone with recent volcanism, and in its axis parts clearly trace a chain of neo-volcanic ridges. Along this neo-volcanic zone the crust is thinner (10-12 km) and has minimum thickness in the central and $\mathrm{NE}$ areas of the zone. Thicker crust $(12-15 \mathrm{~km})$ is defined towards SW. Such a situation lies along SouthShetland Islands, where the thickness of crust increases from $20 \mathrm{~km}$ on the NE to $26 \mathrm{~km}$ on the SW. The same is along the edge of Antarctic Peninsula, where the thickness of crust increases from $14-15 \mathrm{~km}$ on the NE to $19-20 \mathrm{~km}$ on the SW. From the morphological point of view grooves in the central part of the strait can be described as active rift canyon with co-axis volcanic complexes. It is necessary to mark, that this rift has developed on an ancient craton and, probably has no interrelations with spreading of large plates. It intrudes into a continental massif of Paleozoic-Mesozoic rocks in the marginal NW part of the Antarctic Peninsula.

In general, the rift in Bransfield Strait can be a part in the chain of rifts, located from South-Sandwich Island Arc to the continental massif of the Western Antarctic. Active spreading of a rift in SW direction in our times ceased near Deception island. There is the ending of rift grooves and towards SW in a shelf relief of the Antarctic Peninsula there are no similar grooves. But epicenters of earthquakes are tracing up to $70 \mathrm{~km}$ in $\mathrm{SW}$ direction. Thus, the geodynamic factor that causes further intruding of the rift in SW direction already is working here at a distance to our tectonomagnetic investigations area, located in SW direction, of slightly more than $200 \mathrm{~km}$.

The interpretation of defined magnetic field dynamic variations as a result of recent neo-tectonic processes is not clear. Large enough amplitudes of determined tectonomagnetic anomalies, which noticeably exceed similar effects in other seismically active World regions, seem to be caused first of all by outcrops of highly magnetized rocks in the upper part of the crust.
They are some type of indicator of tectonic strain variations in the lithosphere even for large distances.

The obtained results on the features and directions of tectonic strains in the region are confirmed by results of investigations of Earths crust blocks movements, based on the GPS-observations in 2003-2005 (fig. 1). In the Argentine Islands archipelago two different blocks of crust exhibiting different kinematic features have been identified: an eastern block with a horizontal displacement vector towards SE and a western block with horizontal displacements vector towards WNW. They are divided by a tectonic fault (Tretyak et al., 2006).

\section{Conclusions}

As a result of continuous geomagnetic observations in the tectonomagnetic polygon near the location of UAS data about local magnetic field dynamics on the west cost of Antarctic Peninsula were obtained. The spatial-temporal structure of the geomagnetic field variations agrees with tectonic elements. The most intensive tectonomagnetic anomalies were defined on the Three Little Pigs Island. During 19982005 they reached $18.5 \mathrm{nT}$ (2.6 nT per year). The high amplitude of the tectonomagnetic effect is caused by the high magnetization of rocks and the intensive tectonic strains in the crust.

Defined tectonomagnetic anomalies were interpreted as due to the piezomagnetic mechanism. Tectonomagnetic anomalies reflect complex features of interrelations between tectonic strains and magnetic heterogeneities in the upper part of Earth's crust. Blocks of crust in the Argentine Island region are under the influence of stretching horizontal forces near 5 bars per year with a sub-latitude direction.

It was concluded that near UAS lies a submeridian tectonic fault, and in its limits exist active tectonic processes. For the monitoring of their development it is necessary to continue investigations by increasing the number of observation points covering the continental slope of the Peninsula, and the organization of non-stop automatic geomagnetic observations in anom- 
alous zones. The problem of the interrelation of tectonomagnetic observations with other geophysical and geodetic methods remains elusive.

\section{REFERENCES}

HAO, Jin-QI, L.M. Hastie, and F.D. STACEY (1982): Theory of seismomagnetic effect: a reassessment, Phys. Earth and Planet. Inter., 28, 129-140.

MAKsYMChuK, V.Yu., Yu.M. Horodyskyy and V.G. KuZnetsova (2001): Dynamics of Earth's anomalous magnetic field, (Eurosvit, Lviv), pp. 308 (in Ukrainian)

Martin, R.J., R.W. Haupt and R.J. Greenfield (1982): The effect of fluid flow on the magnetic field in low porosity crystalline rock, Geophys. Res. Lett., 9, 13011304.

MizUTANi, H. and T.A. IsHido (1976): A new interpretation of magnetic field variation assotiated with the Matsushiro earthquakes, J. Geomag. Geoelectr., 28, 179186.
MuraKami, H. (1989): Geomagnetic fields produced by electrokinetic sources, J. Geomag. Geoelectr., 41, 221-247.

NAGATA, T. (1969): Tectonomagnetism, IAGA Bull., 27, $12-43$.

PARKInson, W.D. (1983): Introduction to Geomagnetism, (Scottish Academic Press, Edinburgh and London), pp. 528.

SASAI, Y. (1983): A surface integral representation of the tectonomagnetic field based on the linear piezomagnetic effect, Bull. of the Earthquake Res. Inst., 58, 763-785.

SKovorodKIN, Yu.P. (1985): Studyings of tectonic processes be magnetometric methods, (Edition of Earth's physics Institute USSR Ac. Of Sci., Moscow), pp. 197 (in Russian).

Tretyak, K., Yu Golubinka and A. KultchytskyY (2006): Geodynamic investigations of a tectonic fault in the Penola strait (Antarctic peninsula, Argentina islands archipelago). Recent achievements of geodetic science and production, Issue II (vol. 12) (Publishing of the National University «Lviv Polytechnics»), 134140 (in Ukrainian). 